
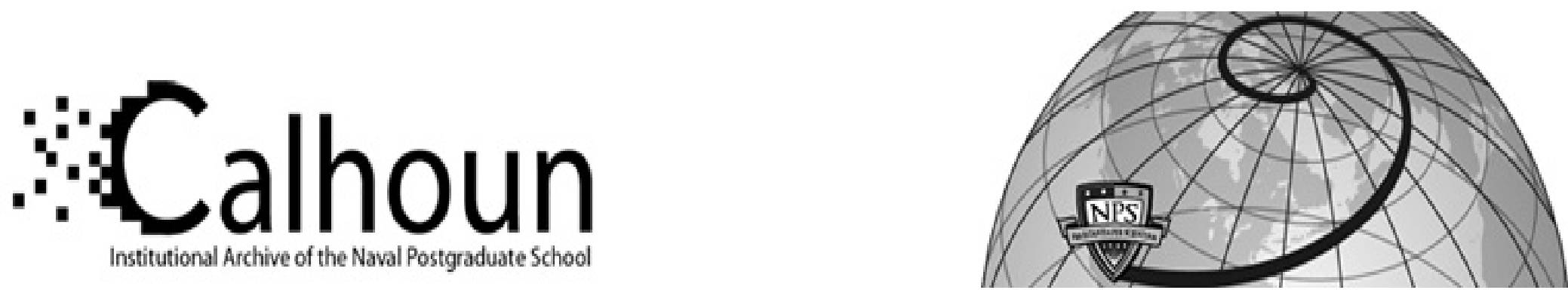

Calhoun: The NPS Institutional Archive DSpace Repository

\title{
Blogs and Military Information Strategy
}

\author{
Kinniburgh, James; Denning, Dorothy E.
}

Kinniburgh, J. and Denning, D. E., Blogs and Military Information Strategy, IO Sphere, Joint Information Operations Center, Summer 2006, pp. 5-13. (.pdf) Also issued as JSOU Report 06-05, Joint Special Operations University, June 2006. Also in Information Strategy and Warfare (J. Arquilla and D. Borer eds.), Routledge, 2007. https://hdl.handle.net/10945/37156

This publication is a work of the U.S. Government as defined in Title 17, United States Code, Section 101. Copyright protection is not available for this work in the United States.

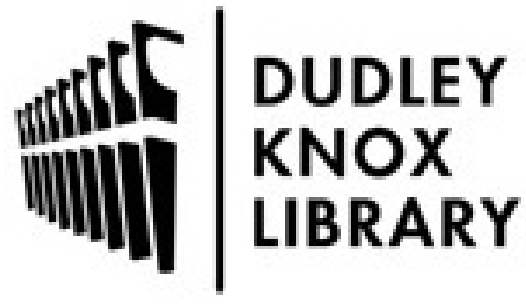

http://www.nps.edu/library
Calhoun is the Naval Postgraduate School's public access digital repository for research materials and institutional publications created by the NPS community. Calhoun is named for Professor of Mathematics Guy K. Calhoun, NPS's first appointed -- and published -- scholarly author.

\section{Dudley Knox Library / Naval Postgraduate School} 411 Dyer Road / 1 University Circle Monterey, California USA 93943 


\title{
Blogs and Military Information Strategy
}

\author{
by James B. Kinniburgh, Major, USAF, and Dr. Dorothy E. Denning
}

Editorial Abstract: The authors explore the potential value of blogs to military information strategy. They examine whether blogs are influential, if the information environment adequately supports blogging for an information campaign, and whether blogs offer a significant, reliable source of intelligence for information operations. They note actual employment of tactics and techniques comes down to cases. Successful employment of blog operations depends on a number of variables that must be determined during intelligence preparation of the environment.

\section{Introduction}

$\mathrm{S}_{\mathrm{s}}^{\mathrm{e}}$ eptember, 2004: the US presidential campaign is in full swing and the producers of the television news show, 60 Minutes Wednesday, received a memo purporting to show sitting President George W. Bush used his family connections to avoid military service obligations. The story, given the controversy and ratings it will generate, is just too good not to run. On cursory inspection, the documents and their source appear legitimate. On September 8th, 60 Minutes producer Mary Mapes, and anchorman Dan Rather decide to air it...

Within minutes of airtime, posted discussion participants at the conservative website FreeRepublic.com posited the documents were faked. Bloggers at Power Line (2004) and Little Green Footballs (littlegreenfootballs.com) picked up these comments and posted them and their associated hyperlinks on their own blogs. What followed initially was what is known as a "blogswarm," where the story was carried on multiple blogs, and then later by a "mediaswarm." As a result of these phenomena, and CBS' inability to authenticate the documents, several CBS employees, including producer Mary Mapes, were asked to resign. Within a month, Dan Rather announced his own retirement.

What garnered considerable interest afterward was how a group of non-professional journalists was able to outperform and "bring down" two icons of the traditional media. CBS executive Jonathan Klein said of the bloggers, "You couldn't have a starker contrast between the multiple layers of checks and balances (at 60 Minutes) and a guy sitting in his living room in his pajamas writing." (Parker)

This article explores the possibility of incorporating blogs and blogging into military information strategy, primarily as a tool for influence. Towards that end, we examine the value of blogs as targets of and/or platforms for military influence operations and supporting intelligence operations

To evaluate the Information Operations (IO) potential for blogs, we seek answers to two questions:

1) Are blogs truly influential, and if so, in what way?

2) Does the information environment support blogging as part of an information campaign?

\section{Blogs and the Blogosphere}

The blogosphere is the world of blogs, bloggers, and their interconnections. It lies mostly within the Web, but it intersects traditional media and social networks as well. To illustrate, The Washington Post features several blogs on its website alongside the newspaper's traditional editorials and op-ed columns, and blog entries often make their way into social networks through e-mail.

\section{Entrenched Inequality and Hierarchy}

The Web is generally considered egalitarian, in that anyone can set up a website. In practice, however, not all nodes are equal. Indeed, the network formed by webpages and their links to each other is often said to follow a power law, meaning the probability that any given node (webpage) is linked to $\mathrm{k}$ number of other nodes, is proportional to $1 / \mathrm{k}^{\mathrm{n}}$ for some constant $\mathrm{n}$ (about 2 for the Web). The power law implies that for any given node in the network, odds are it will have relatively few connections, but there will be a few favored nodes with a disproportionately large number of connections. A network that follows a power law distribution is said to be scale free. (Barabási and Bonabeau)

L Technorati

Blogs by Authority (as measured by links from unique sources)

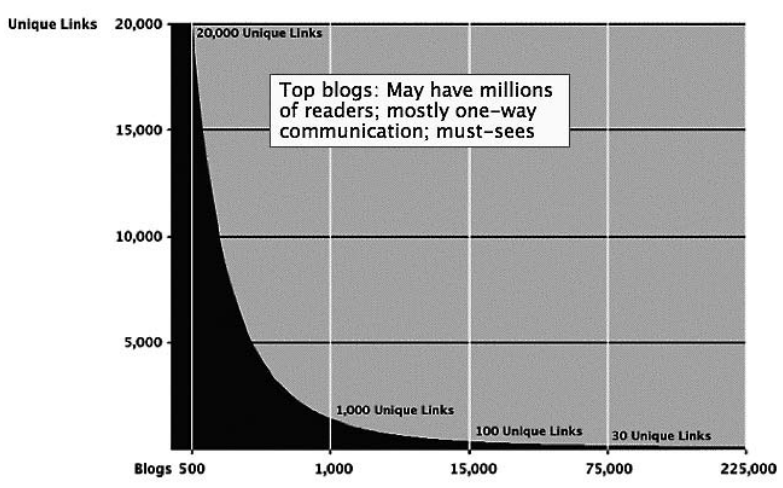

Figure 1.Blog Authority

(Sifry, 13 Feb 2006) 
Research has shown that the blogosphere itself approximates a scale-free net. This is illustrated in Figure 1, which shows the middle part of the curve as computed by Technorati in 2006. (Sifry, 13 Feb 2006) However, the power law may not be an exact fit to the blogosphere. Daniel Drezner and Henry Farrell (July 2004) found that the distribution of links among political blogs was closer to a lognormal distribution rather than a straight power law.

Regardless of whether the power law or lognormal distribution better models the full blogosphere, both distributions are highly skewed. This inequality reflects a hierarchy among blogs. Simply put, a few blogs are extremely popular (have lots of inbound connections), while the majority are hardly noticed or lie somewhere in between. This hierarchy is generally reinforced through a process called "preferential attachment." As a scale-free network grows, the established nodes that are already highly connected tend to pick up the new links. In short, the "rich get richer." The nodes with few connections also gain links, but the overall inequality is reinforced. (Barabási and Bonabeau).

The implications of the entrenched inequality of the blogosphere for influence operations are threefold. First, other things being equal, the blogs that are linked to the most often are likely to be among the most influential. Second, the vast majority of blogs can be ignored, concentrating efforts on the most popular blogs. Third, bringing a new blog into prominence is likely to be slow and difficult. It is not, however, impossible. Technorati, which ranks blogs in terms of the most links from unique sources, found that the third and fifth ranked blogs in February 2006 did not even make the top 100 in April 2005. (Sifry, 13 Feb 2006)

\section{Who Blogs and Why}

According to the Pew Internet and American Life Project (PIP), between February and November of 2004, the numbers of blog readers and blog creators both increased by $50 \%$ or more, reaching about $7 \%$ and $27 \%$ respectively of Internet users (PIP, Jan 2005). However, more recent data from Technorati.com indicates that the blogosphere doubled in size about every six months during a three year period ending in March 2006 (Figure 2). As of April 2006, Technorati.com was tracking 35.3 million weblogs and recording 75,000 new ones each day. (Sifry, 17 Apr 2006) Some of these sites are "splogs" (spam blogs) and not actual blogs. Splogs mimic blogs, but contain entries full of hyperlinked text that directs readers to other sites. From $2 \%$ to $8 \%$ of the blogs created daily in late 2005 were said to fall into this category. (Kesmodel)

With regard to the bloggers themselves, several studies exist that quantify and qualify American Internet users. (PIP, 25 Jan 2005; Lebo and Wolpert). Nearly 75\% of Americans use the Internet regularly, and those who use it most regularly tend to be young, male, have some degree of college education and generally are in or from the middle to upper- middle income brackets. These are the people who tend to be the most politically active, as well. Blog creators follow this

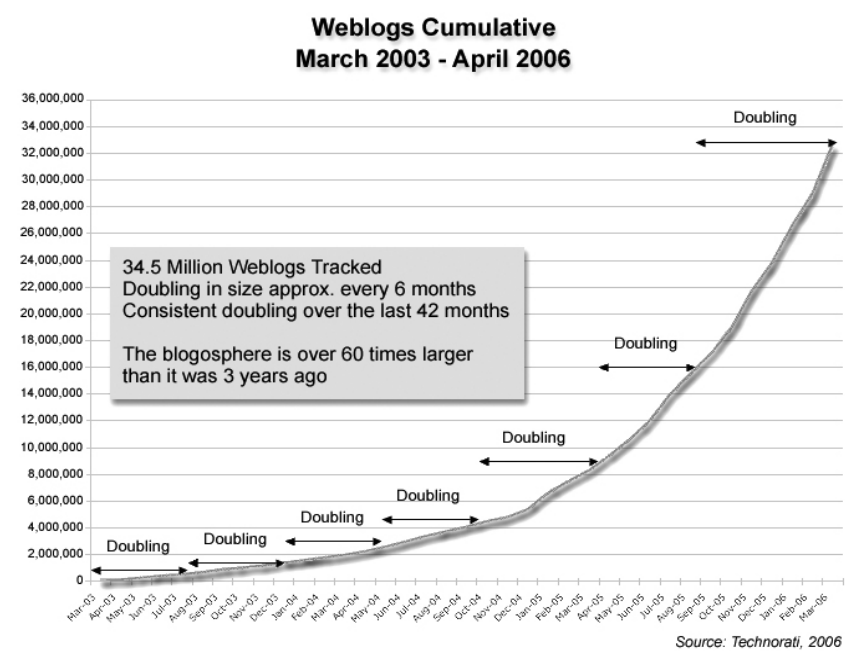

Figure 2. Blog Growth

(Sifry, 17 Apr 2006)

trend, being generally young, affluent, educated males with broadband access and at least six years' experience online (PIP, Jan 2005).

A study by Nardi et al (2004) identifies five major motivations for blogging:

- Documenting the author's life and experiences

- Expressing opinions and commentary

- Venting strong emotions

- Working out ideas through writing (In the words of Shirley Turkle in Life on the Screen, using the blog and computer as "objects to think with")

\section{- Forming and/or maintaining virtual communities}

The number of professional bloggers is likely to increase as the media comes to accept them as legitimate "citizen journalists." In general, a blogger's objectives; qualifications and life experiences; skills at writing, framing arguments and making use of the Web page medium; personal attributes such as integrity; networks of personal contacts; and levels of interaction with the audience all contribute to the audience's assessment of the merit and credibility of his or her blog. According to researcher Kathy Gill of the University of Washington, the most influential blogs were generally written by professionals with excellent writing skills. (Gill, p. 8)

The importance of credibility and reputation to blog influence must be taken into account when considering using a blog as a vehicle for information operations. This is especially critical given the apparent poor image and reputation of the US government in countries we want to influence.

\section{Blog Influence}

As previously observed, blog influence can be affected by the structure of the blogosphere, in particular, the network of hyperlinks connecting one blog to another. To illustrate, imagine starting at any random blog. By following a series of 
links from one blog to another, one is likely to hit one of the top blogs within a few hops. Overall, one is more likely to encounter a well-connected blog, or information posted on it, than one that is not.

Given the multiplicity of networks, their internal connectedness, and the ability of information to hop from one network to another, it would seem that information posted in a blog or elsewhere could reach anywhere. In practice, however, an entity's influence - whether a blog, website, newspaper, television station, person, etc - is seldom so broad. In one study of six social networks, researchers found that individuals were unlikely to be aware of what others in the network were doing if they were more than two hops away. Thus, one's "sphere of observability" was restricted to direct connections and indirect connections involving at most one other person. (Friedkin)

\section{“... There are good reasons to believe that reports of the traditional media's imminent demise are at best exaggerated, and at worst, misleading."}

The converse is that one's "sphere of influence" may likewise be limited to roughly two hops on average. If so, bloggers who are read by journalists working for broadcast media with large audiences can have a potentially much larger sphere of influence than those who are read only by other bloggers or Internet users.

\section{Blogs vs. Traditional Media}

There is a fierce debate both among bloggers and traditional journalists about which media form is most important. Some bloggers, such as Reynolds and other media-watchers, cite a declining viewership of network news broadcasts (Lazaroff), and a drop in circulation of daily US newspapers (2005 circulation was 55.2 million, down from 62.3 million in 1990; Will 2005) as clear evidence that traditional media are on the way out, to be replaced by increasingly influential blogs and other Web-based media. Another data point is the number of bloggers linking to top news and media sites vs. the top blogs. Technorati found that the New York Times, CNN, and The Washington Post still garnered the most links, but the top blog (Boing Boing) beat out such media sites as PBS, Fox News, and Time magazine. (Sifry, 13 Feb 2006)

The existence of a virtual universe of readily available, easily accessible, and good quality information sources may partially explain the dismal ratings traditional news media sources receive. Some Internet theorists (most notably, Howard Rheingold) and market analysts have predicted that the plethora of choices for information consumers means that they will choose only those sources that confirm their own biases without challenging them; moreover, consumers will customize their newsfeeds so as to focus exclusively on a narrow band of interests. However, a recent Pew study (PIP, 6
March 2005) found that most Internet users do not consciously filter out opposing viewpoints, and tend to encounter many diverse viewpoints through sheer accident. Further, many news consumers in the Internet age want interaction, to be able to debate the stories and analyses that interest them. Interactivity is what blogs (and discussion groups) offer that video and print media do not.

On the other hand, there are good reasons to believe that reports of the traditional media's imminent demise are at best exaggerated, and at worst, misleading. For example: The same industry data cited by blog proponents to show the decline in US newspapers' circulation from 1960-2003 actually shows that the decline occurred only for evening editions, whereas morning circulation actually grew and Sunday circulation remained generally constant. (Newspaper Association of America, 2004)

Another reason is that despite the hype surrounding the emergence of blogs as a journalistic format, blogs have been clearly influential in only a few instances, while many other equally compelling stories never made the transition to the mainstream. And this is an important point: without the "mainstream" media's attention, Memogate and the others might never have amounted to anything more than interesting, but obscure historical footnotes.

W.L. Bennett's model of the infosphere (Scott 2005) provides a theoretical framework that explains why this is so. Bennett stratifies the Infosphere into three layers (Figure 3 ): "the conventional layer of mainstream, mass media; the middle layer of prominent blogs, webzines, advocacy groups, etc.; and the micro layer of e-mail, mailing lists, and personal blogs. The most successful communications strategies involve methods of getting a story to access and activate all three strata." (Scott. Italics ours.)

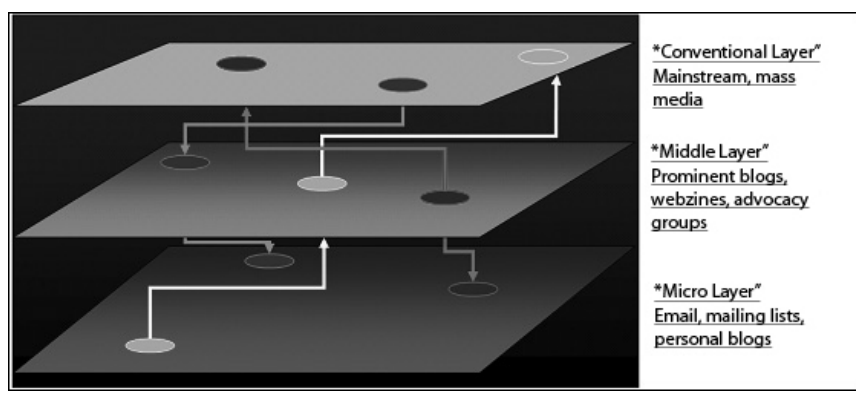

Figure 3. Bennett's Model. Stories can originate in any

layer. The most successful-and influential-are those that spread to and prompt activity on all three layers.

\section{Measuring Influence}

If we can agree, based on the anecdotal evidence, that blogs can be influential and may become more so in the future, it becomes important - as a determinant of the effectiveness of blogging as an IO weapon - to find a way to measure a blog's influence. This section describes various measures that are available today or worth considering. It is not exhaustive of all 
commercially available products and services, but attempts to cover the major metrics and some of their principal providers. We have divided them into two categories: measures based on site visits and measures based on links and citations.

Measures based on site visits include:

- Visitors (aka Reach). This is the number of different users who visit a blog over a given period of time. Alexa (www. alexa.com) computes this measure, which they call Reach, on a daily basis for websites (not just blogs) visited by users of its toolbar.

- Page Views. This is the number of pages viewed on a blog site over a given period of time. Alexa computes this measure on a daily basis for Web pages viewed by their toolbar users.

- Traffic. This is defined by Alexa as the mean of Reach and Page Views averaged over a three month interval and is the measure used to rank websites.

- Interactivity. This is the degree to which a blog's readers offer feedback and participate in discussions with the blogger and other readers.

We are not aware of any efforts to formalize a metric based on interactivity or to rank blogs accordingly. Nevertheless, this measure is potentially valuable, as high interactivity would suggest that visitors to a blog are sufficiently engaged and influenced to respond.

Measures based on links and citations include:

- Inbound Blog Links (aka Authority) This measures the number of other blogs with explicit links (URLs) to a particular blog. Technorati (technoratic.com) ranks blogs on this basis, which it calls Authority. Blogstreet (www.blogstreet.com) also uses this measure to compute a Blog Influence Quotient (BIQ); however, it only counts links in blogrolls (lists of blogs), not links within blog posts.

- Blog Favorites. This measures the popularity of a blog by its inclusion in a Favorites list. Technorati has a Favorites ranking based on information provided by their members.

- Inbound Web Links (aka In-Links). This is similar to Inbound Blog Links, but includes links from anywhere on the Web: blogs, news sites, articles, personal pages, etc. Google (www.google.com) computes this measure through its advanced search feature, but does not offer a ranking of websites based on the measure. PubSub (www.pubsub.com) has a similar measure, which it calls In-Links. Tools such as Link SurveyC also compute this measure.

- Weighted Inbound Web Links (aka Page Rank, Link Rank). This is similar to the preceding, but gives more weight to links from high ranking sites. Google's Page Rank metric falls in this category (www.google.com/technology), as does Pub-Sub's Link Rank. Blogrunner (www.blogrunner.com) is also said to have used a scheme of this type to determine influential bloggers. Their metric was calculated across posts over a 60 day period. (Gill).

- Search Hits. This is the number of hits obtained by searching on the blog name, with qualifiers as needed to distinguish it from other entities, while eliminating hits within the blog's own site (the latter is easily specified with the advanced search option in Google). Search hits will pick up references to a blog that do not include explicit links, but it may also pick up things unrelated to the blog.

- Media References. This is the number of references to a given blog found in the non-Web media, to include radio, television, magazines, journals and newspapers.

- Infosphere References. This is the total number of inbound links and references from all sources at all three layers of the infosphere.

The preceding measures offer different perspectives on blog influence. For example, on April 19, 2005, Technorati showed BoingBoing to be number one in terms of Authority (Inbound Blog Links) but only third in terms of Blog Favorites. Google showed about 91,900 Inbound Web Links and a Page Rank of 9 (out of 10); it returned 10.5 million Search Hits for "boingboing site:boingboing.net," which excludes internal references.

A limitation of the existing metrics is that they are not tailored to any specific domain or demographics. Doing so would be valuable for influence operations. For example, to determine the most influential blog regarding Iraq, one might like a ranking of blogs that address that topic. Or, one might want a ranking of all blogs by Iraqi authors, blogs read by Iraqi's under 30, or blogs receiving the most links from Arab bloggers. The most popular blogs overall might be irrelevant in certain regions or among certain audiences.

Looking back to Bennett's model, for a blog to be truly influential on a national scale, it has to reach and stimulate activity on all three layers of the infosphere, and it has to do this in a skewed system. New blogs constructed for the purpose of conducting PSYOP may have difficulty attracting enough links to reach all three layers. Moreover, the information content must stimulate interest and activity on all three layers, with the limitation that it cannot do so effectively if it appears to be propaganda. This last is especially difficult because of the role that news bloggers tend to adopt: citizen journalists and media watchdogs. Certain existing assets, most notably the Open Source Center (OSC) and the Armed Forces Information Service (AFIS) already cull through thousands of broadcast and print news pieces from around the world, based on topic, and could with relative ease look for blog references as well.

In order to select or design a useful blog for conducting IO, developing measures of the blog's ability to reach and activate the conventional, middle and micro layers of the entire infosphere, as well as the development of a method for measuring the change in attitudes, thinking, beliefs and ultimately actions that are directly attributable to the blog, is critical in order to fine tune military efforts. Selecting or creating a likely candidate blog is the first step, since the hard measure of effectiveness must necessarily come after an operation. As previously noted, a blog's popularity and credibility will be affected by the blogger's perceived reputation, knowledge, and skills. In addition, it is likely to be affected by the perceived quality and credibility of the blog itself. 
Although we know of no studies that correlate with blog popularity or influence, we can draw on research conducted at Stanford on factors that affect the credibility of websites. They found that viewers paid particular attention to design, but that utility and accuracy also mattered. (Fogg et al.) Postings that are well researched and thoughtful, and that bear out this initial assessment, may draw more links than ignorant diatribe, although this is not always the case.

A note of caution is due. As we will see later, the demographics of Internet penetration and use in a given country limits the ability of Web-based media like blogs to reach some target groups, unless the information is picked up by traditional media. A careful analysis of the media environment within the target country must be done before commencing operations.

\section{Implications for Influence Operations}

We began with two research questions: (1) Are blogs truly influential, and if so, in what manner; and (2) Does the information environment support blogging as part of an information campaign?

The answer to the first question is that a small number of blogs are, or have the potential to become, influential in the broadest sense. A blog's influence depends in large part upon the reputation of its author and its content, but also upon the mathematical laws that govern the Blogosphere, and the blog's ability to reach and activate the three primary layers of the infosphere. Blogs that score high in the metrics identified above seem most likely to have influence or become influential.

The answer to the second question is: It depends. One factor to consider is Internet penetration among the population of interest. In some parts of the world, only a small minority of the population has Internet access, and those that do may have similar wealth, education, experiences and outlooks. In such cases, one cannot expect to reach the masses, and intelligence derived from blogs cannot be held to represent views of the majority of the population. On the other hand, as noted earlier, information posted to blogs can jump to traditional media and travel through social networks. Hence, even if members of a population do not have access to the Internet or read a particular blog, they may be influenced by it if local elites, including mainstream media elites, do.

Some countries such as China censor the Internet, prohibiting their citizens from publishing certain information on a website or blog, or from accessing certain sites. In that environment, it may be hard to get a complete intelligence picture from bloggers inside the country or to influence the population with a blog that may be subject to censorship. On the other hand, blogs that serve a small community, or that fill a specific niche may be useful for monitoring and targeting select elements. People may and do serve in more than one social capacity; they may represent a class of community or peer opinion leaders - useful as both targets of influence operations and as vehicles for disseminating strategic communications.

This discussion of communities leads us to another point of difficulty in using blogs for IO. Segmentary opposition and its gentler cousin, in-group/out-group dynamics, may prevent a foreign audience from taking an overtly US government-run or sponsored blog seriously. Even American blogs show a high incidence of ethnic clustering (Choi), and the deep-seated fissures between major tribal groups, and often between subgroups, frequently define traditionally tribal societies like those in Afghanistan. Even if there is no widespread preconception about US use of propaganda, it may be easy for foreign audiences to dismiss the US perspective with "Yes, but you aren't one of us, you don't really understand us."

In this regard, information strategists can consider clandestinely recruiting or hiring prominent bloggers or other persons of prominence already within the target nation, group, or community to pass the US message. In this way, the US can leap over the entrenched inequalities and make use of preexisting intellectual and social capital. Sometimes numbers can be effective; hiring a block of bloggers to verbally attack a specific person or promote a specific message may be worth considering. (Lyons. 2005) On the other hand, such operations can have a blowback effect, as witnessed by the public reaction following revelations that the US military had paid journalists to publish stories in the Iraqi press under their own names. (Mazzetti and Daragahi.) People do not like to be deceived, and the price of being exposed is lost credibility and trust.

An alternative strategy is to "make" a blog and blogger. The process of boosting the blog to a position of influence could take some time, however, and depending on the person running the blog, may impose a significant educational burden, in terms of cultural and linguistic training before the blog could be put online to any useful effect. Still, there are people in the military today who like to blog. In some cases, their talents might be redirected toward operating blogs as part of an information campaign. If a military blog offers valuable information that is not available from other sources, it could rise in rank fairly rapidly.

Any blogs and bloggers serving an IO mission must be coordinated and synchronized with the overall influence effort in time and message. However, they must be prepared to argue and debate with their audience successfully and independently on behalf of the US policy stance. In this sense, bloggers must be able to "circumvent the hierarchy" as blogger George Dafermos (2004) put it. This means that they must be trusted implicitly to handle the arguments without forcing them to communicate "solely by means of marketing pitches and press releases."

There are certain to be cases where some blog, outside the control of the US government, promotes a message that is antithetical to US interests, or actively supports the informational, recruiting and logistical activities of our enemies. The initial reaction may be to take down the site, but this is problematic in that doing so does not guarantee that the site will remain down. As has been the case with many such sites, the offending site will likely move to a different host server, often in a third country. Moreover, such action will likely produce even more interest in the site and its contents. Also, taking down a 
site that is known to pass enemy EEIs (essential elements of information) and that gives us their key messages denies us a valuable information source. This is not to say that once the information passed becomes redundant or is superseded by a better source that the site should be taken down. At that point the enemy blog might be used covertly as a vehicle for friendly information operations. Hacking the site and subtly changing the messages and data - merely a few words or phrases - may be sufficient to begin destroying the blogger's credibility with the audience. Better yet, if the blogger happens to be passing enemy communications and logistics data, the information content could be corrupted. If the messages are subtly tweaked and the data corrupted in the right way, the enemy may reason that the blogger in question has betrayed them and either take down the site (and the blogger) themselves, or by threatening such action, give the US an opportunity to offer the individual amnesty in exchange for information.

There will also be times when it is thought to be necessary, in the context of an integrated information campaign, to pass false or erroneous information through the media, on all three layers, in support of military deception activities. Given the watchdog functions that many in the blogging community have assumed - not just in the US, but also around the world - doing so jeopardizes the entire US information effort. Credibility is the heart and soul of influence operations. In these cases, extra care must be taken to ensure plausible deniability and nonattribution, as well as employing a well thought-out deception operation that minimizes the risks of exposure. Because of the potential blow-back effect, information strategy should avoid planting false information as much as possible.

This brings us to an even more fundamental issue. Because the US military is prohibited from conducting information operations against US persons, it is reluctant to engage in Internet IO, especially anything that might be characterized as PSYOP or deception. Once information is on the Internet, it can reach anyone, including those in the US Thus, while the military offers factual news on the Internet through Public Affairs, it generally stays away from commentary and IO. At least initially, this challenge might be addressed by sticking with accurate, factual information of value to readers. Blogging can support PA and focus on improving communications and building trust with local communities and the public. A blog can be used to solicit and respond to questions and concerns from target populations. In addition, military leaders might offer personal commentary on non-military blogs, with the usual disclaimers."

To use blogs effectively for an information campaign may require a new intelligence tool, one that can monitor and rapidly assess the informational events occurring in a specific portion of the blogosphere and their effects (if any) on the three layers of the local infosphere.

\section{Blogs and Intelligence}

Web-log derived intelligence can be considered a subset of both communications intelligence (COMINT) and open- source intelligence (OSINT). We would expect to see it used primarily in support of information operations, although it does offer a broad range of possible applications. It may consist of computer network exploitation (CNE) done in support of integrated PSYOP, PA, PD, MILDEC, and CA/CMO operations. The value of using blogs and blogging in support of a military information strategy depends heavily on the target region's Internet penetration and regulation (especially censorship). Further, if the number of Internet users is small, it is necessary to determine who is using the capability and why. Again, this very basic information should be collected as a part of the initial intelligence preparation of the environment, but once obtained it becomes a significant part of the baseline assessment for determining the need for, and the value of, conducting blog-based information operations.

If assessment of the information environment indicates the presence of blogging activity, the next step is to look at the bloggers and their audiences, determine the blogs' functions (per Nardi et al), and construct a preliminary analysis in terms of the metrics (blog visits and incoming links and references) and indicators of quality and credibility (design, utility, accuracy, and currency) identified earlier. Questions include:

- How large is the blogging community?

- Who are the bloggers? And what are their positions and status within their communities and within the country as a whole (their general public roles and reputations)?

- Who is the target community or audience for each blog?

- Do the blogs address issues of social and political importance to the community they serve?

- What biases are observed in each blog? Do they reinforce or challenge the biases of their audience?

- Do any bloggers invite and engage in free and open interaction with their audience?

Answering these questions will require appropriate responses from intelligence agencies at all levels. Nationallevel agencies are perhaps best suited to conduct comprehensive media, human factors and social network analyses to identify and characterize the prominent and/or influential bloggers within their social networks, and their connections to the larger community of traditional media journalists. These agencies should also examine the frequency with which each blog is referenced in the other media in the target region, and perhaps engage in $\mathrm{CNE}$ to study reactions and references in the micro layer.

The importance of interactivity to a blog's influence is proportional to the size of the blog's potential audience. In areas where Internet access is limited to top government officials only, interactivity may be of relatively low importance. In areas where a ruling or elite social class has access, interactivity can be more important. In countries where Internet access is widespread, but free exchange of ideas is limited and/or discouraged, interactivity becomes golden. 
Social network analysis and human factors analysis must be combined and correlated to craft specific messages to target specific bloggers and members of their audiences. Combined with a good sociological, psychological and cultural framework for interpreting and predicting attitudes, behaviors, communications and actions, intelligence derived from and/or about blogs can be highly effective in supporting influence and counter-influence campaigns.

The entrenched inequality that characterizes the blogosphere has some implications for intelligence analysis and assessment. On the positive side, the fact that the most influential blogs generally will be the most authoritative (i.e., have the highest number of links) limits the number of blogs that must be read to glean the key or most widely held perspectives, concerns, attitudes and knowledge that motivate the audience. A survey of only these blogs can provide a rapid method for assessing the effectiveness of other influence operations in much the same way that a Civil Affairs soldier can assess general attitudes and mood by reading the graffiti on the walls. On the down side, in heavily Internetted regions, the tendency toward monopoly that results from systemic self-optimization will result in increasing homeostasis. Authors of top blogs in these environments may become disconnected from the content of their blogs and the concerns of their audience. This is because the needs of maintaining the blog may override the ability of the blogger to survey other blogs, conduct research and maintain interactivity. Because of this tendency, and in areas where only the elites or the government have Internet access, the content of the top blogs may not correlate well with majority concerns/opinions. As always, intelligence drawn from blogs may be invalid without confirmation from other sources.

Analysts working with blog intelligence must have access to the operational disciplines that they support; the closer the better. We recommend the creation of small special operations units with operational authority and integrated intelligence collections and analysis to conduct blog-based operations.

Recently, analysts at the Open Source Center under the auspices of the Director of National Intelligence (DNI) have been monitoring and following significant foreign blogs and bloggers with the primary goal of exploiting them as sources of intelligence. A February 2006 posting on the organization's "Blog on Blogs" about Iranian expatriate blogger Hossein Derakhshan ("Hoder"), described him as "one of the most influential Iranian bloggers." OSC analysts used Traffic (based on Reach and Page Views) from Alexa, Authority (Inbound Blog Links) from Technorati, and frequency of postings from BlogPulse. All three sources share the advantage of ready availability, but are limited for reasons discussed earlier.

\section{Blog-Based Operations}

To function most effectively, units conducting blog-based operations must be staffed appropriately. Ideally, such units would be drawn from the special operations and intelligence communities, because of their historical experience in and

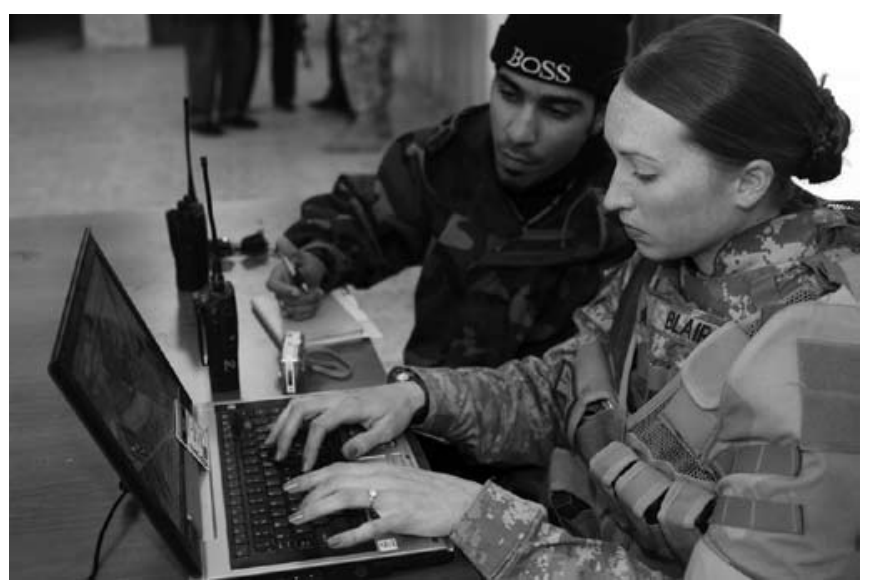

Every soldier is a potential blogger (DefenseLink)

ability to conduct (when tasked) sensitive operations. Linguists and intelligence analysts (preferably analysts who are also linguists), who are commanded or advised by qualified PSYOP or IO officer should form the core of such a unit. These capabilities must be augmented through liaison relationships with the other influence organizations, those responsible for planning and conducting PSYOP, PA, PD, CA/CMO and MILDEC. Because of the unique nature of blog-related intelligence, comprising both open and highly classified sources and producing an output intended for open distribution, a blog operations unit should have solid information, operations, and network security programs in place. It also needs oversight.

In order to act and react efficiently in managing bloggers and blogs, the intelligence specialists and planners who have the knowledge should be the ones running the actual blog. Or, in cases where indigenous bloggers and their blogs have been identified and recruited, the blog operations cell should also house the case officer managing the asset, having done the work to cultivate and recruit him or her. The same metrics used to select a blog can also serve as indirect measures of effectiveness; for example:

- Once blog operations have begun, does the blog attract new inbound links?

- Is there an increase over time in the blog's ranking via various metrics?

- Through polling and media analysis, can a change in public opinion be correlated with growth in the blog's indicators?

- What does content analysis of the interaction that occurs with the blogger on the site reveal (change in opinions posted by readers? Positive or negative?)

- Do the comments on the blog correlate with public opinion results obtained by polling and/or portrayed in the mainstream media?

- Does the blog get referenced by the mainstream media in the target country, and with what degree of frequency?

- Do other sources of intelligence confirm these indicators? 
Like any other influence operation, blog operations must be given time to work. There are no magic bullets. We would suggest quarterly reviews of the blog's effectiveness along these lines and then adjusting fire to reverse any negative trends and accelerate positive trends.

This fusion of intelligence and operations is the cost of and the requirement for operating in a medium that rewards the efficient distribution of knowledge and information above all other considerations, and is also in the best traditions of the intelligence and special operations communities. Pushing operational authority out to those best equipped to receive, analyze and act in a dynamic information environment maximizes both efficiency and effectiveness. Although a blog-based operations unit could be based either domestically or in theater, the best option is to forward deploy it as a cell, just as we deploy our PSYOP analysts and production and dissemination capabilities.

\section{Conclusions}

Over the course of this article, we have shown some of the potential uses of the blogging phenomenon for military information strategy. While we can make reasonably certain statements about blogging in general that can be applied universally, the actual employment of tactics and techniques comes down to cases. The successful employment of blog operations depends on a number of variables that must be determined during intelligence preparation of the environment. In environments that support them, properly conducted blog operations have the potential to be extraordinarily powerful, as demonstrated by the high profile incidents involving blogs during the 2004 presidential campaign.

Some of the possible techniques we have explored in our discussion of the military use of blogging require a certain degree of subtlety, finesse, and yes, covert action. By giving military blog-based operations to the Intelligence and special operations communities, these uses become less risky and more feasible. However, military operations must necessarily remain only a part of a larger effort. Given the current state of US and international law, and the distribution of the necessary authorities among many (often competing) government agencies, any future conduct of influence operations through the blogosphere will require a truly integrated interagency approach, and thus belongs properly at the national level as a part of an over-arching strategic communication effort.

One of the significant limitations of this article, as an initial foray into military use of the blogosphere, is that much of the information available concerns American blogs, run by Americans, largely for an American audience. Military use of the blogosphere must necessarily focus on foreign blogs, bloggers and audiences. However, because some factors, such as the scale-free nature of the Internet and the psychological basis of influence are universals, we hope to lay a general basis for military use of the blogosphere that can be adapted to specific tactical circumstances by information operators.

\section{Bibliography}

Barabási, A.L. and Bonabeau, E. (2003). "Scale-Free Networks." Scientific American. May 2003. Pp. 6069. (2003). Abstract from "Hierarchical Organization in Complex Networks." Physical Review E. Abstract cited: http://scitation.aip.org.

Choi, H. (2003). "Ethnic Clustering in Blogging Communities." Retrieved 30 Sep 2005 from: http://www.students. haverford.edu/hchoi/final\%20project.htm.

Dafermos, G. (2004). "Blogging the Market: How Weblogs are turning corporate machines into real conversations." Retrieved 28 Sep 2005 from http://opensource.mit.edu/papers/dafermos3.pdf.

DNI Open Source Center. (2 Feb 2006) "OSC Analysis 2 Feb: Cartoons of Muhammad Spark Rising Controversy." Retrieved 7 February 2006 from: https:/www.fbis.gov/portal/server.pt/gateway/PTARGS___ _ 32553_4361_240_240_43/http\%3B/apps.fbis.gov\%3B7011/fbis.gov/content/ Display/5894891?action=advancedSearch.

Drezner, D. and Farrell, H. (July 2004). "The Power and Politics of Blogs." Paper presented to the 2004 American Political Science Association. Retrieved 2 October 2005 from: http://www.utsc.utoronto.ca/.

Fogg, B. J. et al. (2002). "How Do People Evaluate a Web Site's Credibility?" Consumer Reports WebWatch. October 29, 2002. Retrieved 5 October 2005 from http://www. consumerwebwatch.org/.

Friedkin, N.E. (1983). "Horizons of Observability and Limits of Informal Control in Organizations." Social Forces. Vol. 62:1. September 1983. Pp. 54-77.

Gill, K. (2004). "How Can We Measure the Influence of the Blogosphere?” Retrieved 29 Sep 2005 from: http://faculty. washington.edu/kegill/pub/www2004_blogosphere_gill. pdf.

Kesmodel, D. (19 Oct 2005). "'Splogs' Roil Web, and Some Blame Google." The Wall Street Journal Online. p. B1. Retrieved 26 October 2005 from: http://online.wsj.com/ public/article/SB112968552226872712-8b51_fijhNltE4s7DX6tvLI9XNo_20061025.html.

Khanoon, B. (12 Dec 2005). "Hoder: One of the Most Influential Iranian Bloggers." Blog on Blogs. DNI Open Source Center. Washington, DC. Retrieved 7 February 2006 from: https://www.fbis.gov/portal/server.pt/gateway/PTARGS_0_32553_3892_240_0_43/http;/apps.fbis. gov;7011/fbis.gov/blogs/page/blogsblog003/20051213.

Lazaroff, L. (24 Nov 2004.) "Audience Decline an Old Story.” Chicago Tribune Online. Retrieved 15 Aug 2005 from: http://www.csupomona.edu/ jrballinger/448/readings/News_Audience_decline.htm.

Lebo, H. and Wolpert, S. (14 Jan 2004). "First Release of Findings from the UCLA World Internet Project Shows Significant 'Digital Gender Gap' in Many Countries,' UCLA News. Retrieved 14 Jan 2004 from: http://www. uclanews.ucla.edu. 
Lyons, D. (Nov 2005). “Attack of the Blogs.” Forbes Online. Retrieved 5 Nov 2005 from: http://www.forbes.com/ forbes/2005/1114/128_print.html.

Mazzetti, M. and Daragahi, B. (30 Nov 2005). "US Military Pays to Run Stories in Iraqi Press," Los Angeles Times.

Nardi, B., Schiano, D., Gumbrecht, M. and Swartz, L. (2004). "'I'm Blogging This: A Closer Look at Why People Blog." Paper submitted to Communications of the ACM. Retrieved 15 Sep 2005 from: http://www.ics.uci. edu/ jpd/classes/ics234cw04/nardi.pdf.

Newspaper Association of America. (2004). Facts About Newspapers: A Statistical Summary of the Newspaper Industry. Retrieved 29 April from http://www.naa.org/info/ facts04/circulation-daily.html.

Parker, K. (15 Sep 2004). "Bloggers Knew!” Article on TownHall.com. Retrieved 20 Sep 2005 from: http://www. townhall.com/columnists/kathleenparker/kp20040915. shtml.

Pew Internet and American Life Project (PIP).

(Jan 2005). "The State Of Blogging." Retrieved 19 Apr 2006 from: http://www.pewinternet.org/pdfs/PIP_blogging_data. pdf.

(25 Jan 2005). A Decade Of Adoption: How The Internet Has Woven Itself Into American Life. Retrieved $21 \mathrm{Sep}$ 2005, from: http://www.pewinternet.org/PPF/r/148/report_display.asp.

(6 Mar 2005). The Internet and Campaign 2004. Retrieved from: http://www.pewinternet.org/pdfs/PIP_2004_Campaign.pdf.

Powerline. (9 Sep 2004). "The Sixty-First Minute.” Retrieved 19 April 2006 from: http://powerlineblog.com/archives/007760.php.

Reynolds, G. (27 April 2005). "Are Blogs Busting Loose?”
Retrieved June 05 from: http://www.techcentralstation. com/042705B.html.

Rheingold, H. (2002). Smart Mobs: The Next Social Revolution. New York: Perseus Publishing.

Scott, D. (2005). Tempests of the Blogosphere: Presidential Campaign Stories that Failed to Ignite Mainstream Media. MIT. Retrieved 20 Sep 2005 from: http://web.mit. edu/comm-forum/mit4/papers/scott.pdf.

Shirky, C. (10 Feb 2003). Power Laws, Weblogs, and Inequality. Retrieved 10 Jul 2005 from: http://www.shirky. com/writings/powerlaw_weblog.html.

Sifry, D. (17 Apr 2006). "State of the Blogosphere, April 2006, Part 1: On Blogosphere Growth," Technorati Weblog. Retrieved 18 Apr 2006 from http://www.sifry. com/alerts/.

Sifry, D. (13 Feb 2006). "State of the Blogosphere, February 2006, Part 2: Beyond Search,” Technorati Weblog. Retrieved 18 Apr 2006 from http://www.sifry.com/alerts/.

Turkle, S. (1995). Life on the Screen: Identity in the Age of the Internet. New York: Simon \& Schuster.

Wikipedia

(20 Aug 2005). "Fourth Estate." Wikipedia, the Free Encyclopedia. Retrieved 20 Sep 2005 from http://en.wikipedia. org/wiki/Fourth_estate

(3 May 2006) "Jeff Gannon." Wikipedia, the Free Encyclopedia. Retrieved 5 May 2006 from http://en.wikipedia. org/wiki/Jeff_Gannon

Will, G. F. (24 Apr 2005). "Unread and Unsubscribing." The Washington Post. P. B07. Retrieved 15 August 2005 from: http://www.washingtonpost.com/wp-dyn/articles/A106982005Apr22.html

Winer, D. (24 Mar 2004). "Session: Shirky’s Power Law." Retrieved 25 June 2005 from: http://www.bloggercon.org )

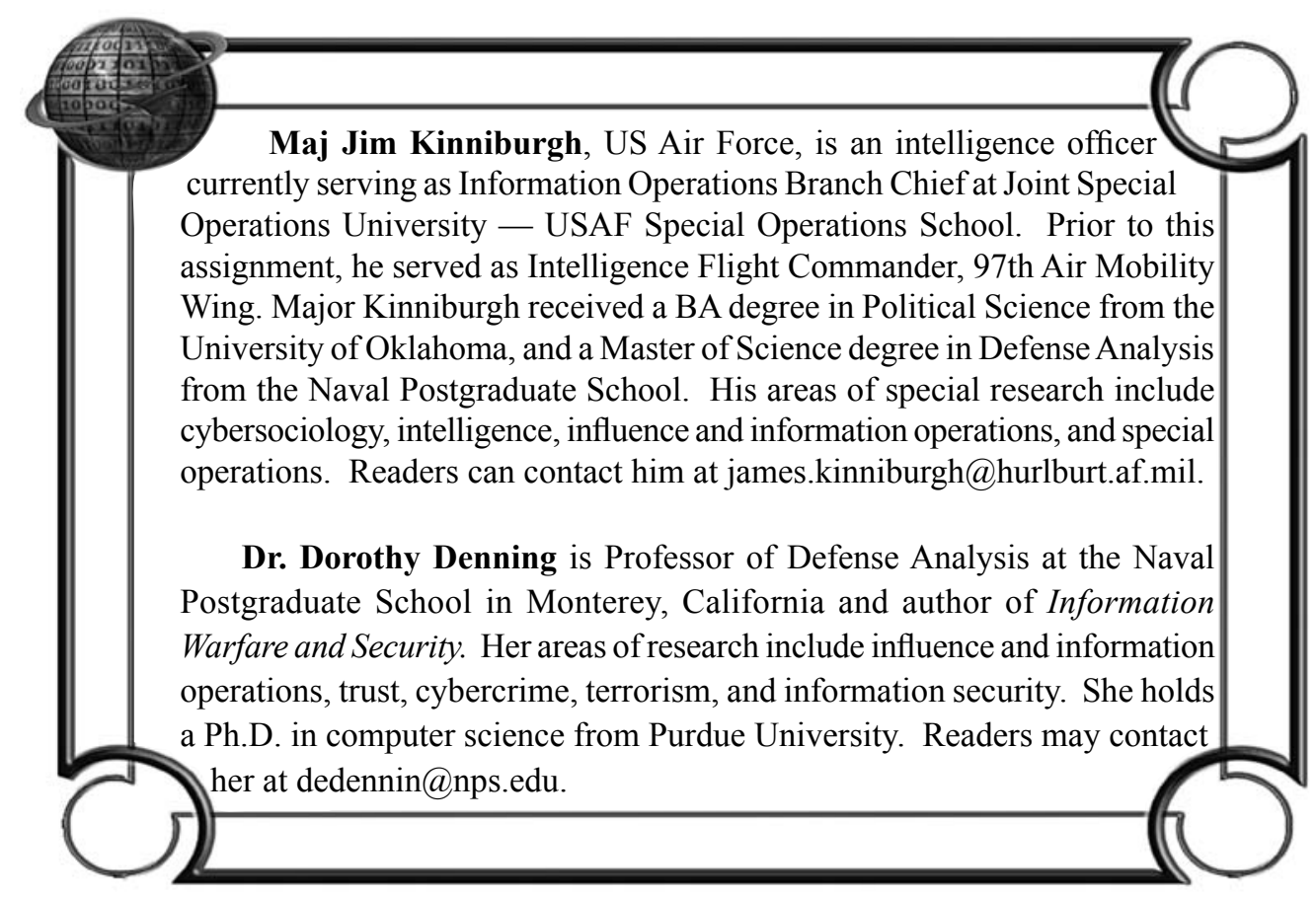

